\title{
Esterification of Hemins with Trimethyloxonium Tetrafluoroborate
}

\author{
Richard T. Dean, Louis J. DeFilippi, and Donald E. Hultquist \\ Department of Biological Chemistry, The University of Michigan, \\ Ann Arbor, Michigan 48109
}

Received July 26, 1974: accepted June 22. 1976

A procedure has been developed for the methylation of hemins using trimethyloxonium tetrafluoroborate. The method is rapid and selective for carboxyl groups, and it can be used to methylate polar and nonpolar hemins under neutral and basic conditions. Esterifications of protohemin IX, hematohemin, and heme $a$ have been accomplished in high yield.

Esterification of naturally occurring hemins and porphyrins is often a prerequisite for structural studies of these compounds. Porphyrins and hemins are in general more easily purified as their esters than as the free carboxylic acids. In addition, esterification is the most feasible procedure for preparing derivatives of tetrapyrroles for studies by mass spectrometry.

The most convenient and frequently employed method for hemin and porphyrin esterification has been treatment with an alcohol and mineral acid. Although this method is highly successful in derivatizing the carboxyl group, bond cleavage or rearrangement of various acid-labile tetrapyrroles may result from the strongly acidic conditions, and derivatization of other functional groups may occur. For example, treatment of heme $a$ with methanol-sulfuric acid results in partial methylation of both the formyl and hydroxyl groups (1). Although porphyrins can be esterified with diazomethane, this reaction may very well modify side chains and is completely unsuitable for hemin carboxylic acids (2). Conversion of an acid-labile hemin to its porphyrin methyl ester by way of the free porphyrin is not feasible since removal of iron from the hemin requires acid conditions.

Recent studies in this laboratory have been directed toward determining the structure of the unique formylhemin prosthetic group of a green hemeprotein isolated from human and bovine erythrocytes $(3,4)$. The very labile character of the isolated hemin has led us to suspect the presence of a moiety which can be cleaved or derivatized in acid. An acid-labile group has likewise been postulated to be a component of the hemin prosthetic group of cytochrome oxidase (5). Thus, a method of esterification which would selectively derivatize carboxyl groups of 
hemins under mild, neutral conditions would be of great benefit in studying the structure of the hemin of the erythrocyte protein, heme $a$, and any other hemins suspected of containing an acid-labile group. This communication reports the use of trimethyloxonium tetrafluoroborate in neutral and basic solution for the selective methylation of the carboxyl groups of protohemin IX, hematohemin, and heme $a$. A preliminary report of this work has appeared in abstract form (6), and the reaction of the prosthetic group of the erythrocyte green hemeprotein with trimethyloxonium tetrafluoroborate has been reported (4).

\section{EXPERIMENTAL PROCEDURE}

Materials. ${ }^{1}$ Benzilic acid was obtained from Aldrich Chemical Co., $N, N$-diisopropylethylamine from Pfaltz and Bauer, 2,6-lutidine, epichlorohydrin, and boron trifluoride diethyl etherate from Eastman, and dimethyl ether from Matheson. Chromatographic grade alumina was obtained from Merck. Polyamide plates $(8 \times 8 \mathrm{in}$.) for thin-layer chromatography were obtained from Gallard-Schlesinger. Methanol was distilled over magnesium methoxide. Ethanol (95\%) was used without purification. Chloroform was washed with water, dried over $\mathrm{CaCl}_{2}$, and distilled. Pyridine was distilled from ninhydrin and stored over $\mathrm{KOH}$ pellets.

Protohemin IX chloride was isolated from human erythrocytes by the method of Fisher (7). Heme $a$ was isolated from beef heart cytochrome oxidase by the method of York et al. (8) and was quantitated spectrophotometrically as its reduced pyridine hemochrome $(1,9)$. Purified hematohemin chloride was a gift from Dr. Takashi Yonetani and was repurified immediately prior to use by preparative thin-layer chromatography on polyamide (10); the plates were developed with a solution of $2.5 \%$ acetic acid in methanol and the band of hematohemin was eluted from the plate with pyridine.

$\mathrm{Me}_{3} \mathrm{OBF}_{4}$ was prepared by reaction of boron trifluoride diethyl etherate, dimethyl ether, and epichlorohydrin using the apparatus and precautions described by Curphey (11). Dimethyl ether was passed into a flask containing $80 \mathrm{ml}$ of methylene chloride and $34 \mathrm{ml}(0.27 \mathrm{~mol})$ of boron trifluoride diethyl etherate until approximately $75 \mathrm{ml}$ had collected. Epichlorohydrin $(24 \mathrm{ml}, 0.307 \mathrm{~mol})$ was then added dropwise with vigorous stirring over a $15-\mathrm{min}$ period and the mixture was stirred overnight. The supernatant was removed from the crystalline trimethyloxonium tetrafluoroborate. The oxonium salt was washed with two 100 -ml portions of anhydrous methylene chloride and two $100-\mathrm{ml}$ portions of dry diethyl ether, and then dried under a stream of nitrogen.

\footnotetext{
${ }^{1}$ The abbreviations used are: $\mathrm{Me}_{3} \mathrm{OBF}_{4}$, trimethyloxonium tetrafluoroborate: $\mathrm{nmr}$, nuclear magnetic resonance; ir, infrared; tlc, thin-layer chromatography.
} 
General methods. Methylation reactions with $\mathrm{Me}_{3} \mathrm{OBF}_{4}$ were carried out by modification of the conditions reported earlier for the esterification of amino acids (12). The extent of reaction was determined by paper chromatography and by polyamide thin-layer chromatography. Ultraviolet and visible spectra were determined with a Cary Model 14 spectrophotometer, nmr spectra with a Varian T-60 spectrometer, and mass spectra with an AEI MS 30 spectrometer. Reduced pyridine hemochromes of hemes were characterized by their visible spectra (9).

Methylation of benzilic acid. Benzilic acid<smiles>O=C(O)C(O)(O)C(=O)O</smiles>

was used as a model compound for assessing the specificity of methylation by $\mathrm{Me}_{3} \mathrm{OBF}_{4}$. The reaction of benzilic acid was carricd out at room temperature using a $10 \mathrm{M}$ excess of $\mathrm{Me}_{3} \mathrm{OBF}_{4}$. Benzilic acid $(8.77 \mathrm{mmol})$ was dissolved in $110 \mathrm{ml}$ of water containing sodium bicarbonate $(96.7$ mmol). $\mathrm{Me}_{3} \mathrm{OBF}_{4}(87.9 \mathrm{mmol})$ was added to this solution in small portions with rapid stirring over a 5 -min period and the reaction mixture was allowed to stir for an additional $15 \mathrm{~min}$. The reaction mixture was extracted with ether. The ether extract was washed twice with $150 \mathrm{ml}$ of $5 \%$ aqueous $\mathrm{NaHCO}_{3}$ and twice with water, dried over $\mathrm{Na}_{2} \mathrm{SO}_{4}$, and filtered. Solvent evaporation yielded $1.75 \mathrm{~g}(82.4 \%$ of theoretical $)$ of a white, crystalline solid which migrated as one spot on thin-layer chromatography (silica gel. using ethyl acetate, $\left.R_{f} 0.67\right)$ and was insoluble in water and soluble in hot ethanol.

The isolated product was identified as methyl benzilate<smiles>COC(=O)C(C)(O)O</smiles>

by melting point and by $\mathrm{nmr}$, ir, and mass spectra. The melting point (uncorrected) of $71.5-72.5^{\circ} \mathrm{C}$ is in agreement with the value of $73^{\circ} \mathrm{C}$ reported in the literature for methyl benzilate (13). An ir spectrum in Nujol showed strong absorbances at $3510 \mathrm{~cm}^{-1}(-\mathrm{OH})$ and $1720 \mathrm{~cm}^{-1}$ $(\mathrm{C}=\mathrm{O})$; triethylamine caused no shifts, indicating the absence of a free carboxyl group. In contrast, benzilic acid showed strong absorbance at $3390 \mathrm{~cm}^{-1}(-\mathrm{OH})$ and $1720 \mathrm{~cm}^{-1}(\mathrm{C}=\mathrm{O})$, with the latter peak shifting to $1643 \mathrm{~cm}^{-1}$ in the presence of triethylamine. The mass spectrum showed a molecular ion at $m / e 242$. which corresponds to a monomethyl derivative, 
and a fragmentation pattern with major peaks at $241,225,183,165$, and 77 mass units, which is only compatible with the methyl ester. An nmr spectrum in $\mathrm{CDCl}_{3}$ showed singlets at 2.6, 5.8, and 6.1 $\tau$. Integration of these peaks showed 10,1 , and 3 hydrogen atoms, respectively.

Methylation of protohemin IX. Protohemin IX (25.4 mg, $0.0412 \mathrm{mmol})$ was dissolved in a mixture of $0.15 \mathrm{ml}(0.84 \mathrm{mmol})$ of diisopropylethylamine. $1.0 \mathrm{ml}$ of water, and $9.0 \mathrm{ml}$ of $95 \%$ ethanol. Three $30-\mathrm{mg}$ batches of $\mathrm{Me}_{3} \mathrm{OBF}_{4}$ (total of $0.61 \mathrm{mmol}$ ) were added to this solution over a 10 -min period with vigorous stirring at room temperature. The reaction proceeded without formation of a precipitate or turbidity. Ten minutes after the last addition of $\mathrm{Me}_{3} \mathrm{OBF}_{4}, 25 \mathrm{ml}$ of chloroform and then $50 \mathrm{ml}$ of water were added. Shaking of the mixture resulted in the quantitative extraction of the color into the chloroform phase. The chloroform phase was washed twice with $50 \mathrm{ml}$ of water and then dried first with solid $\mathrm{NaCl}$ and then with $\mathrm{Na}_{2} \mathrm{SO}_{4}$. The solvent was removed by rotary evaporation at room temperature and then desiccation in a vacuum. The procedure yielded $26.5 \mathrm{mg}(0.0412 \mathrm{mmol}, 100 \%$ of theoretical $)$ of protohemin IX dimethyl ester.

The methylation was monitored by subjecting aliquots of the reaction mixture to thin-layer chromatography on polyamide plates using $10 \%$ acetic acid in benzene as solvent (10). After the first 30-mg addition of $\mathrm{Me}_{3} \mathrm{OBF}_{4}$, two products were detected: a spot with an $R_{f}$ of 0.47 , corresponding to the dimethyl ester, and a spot with an $R_{f}$ of 0.19 , presumably corresponding to the monomethyl ester(s). In this system free protohemin IX showed an $R_{f}$ of 0.03 . It was estimated that the first addition of oxonium salt resulted in methylation of $90 \%$ of the carboxyl groups, while the second and third treatments completed the reaction as seen by tlc. After the addition of the two subsequent batches of methylating agent, polyamide chromatography revealed the presence of a single species only, with an $R_{f}$ corresponding to the dimethyl ester. This final product also migrated as a single spot on paper chromatography with $n$-propanol: kerosene $(9: 50, \mathrm{v} / \mathrm{v})$.

The product was identified as the dimethyl ester of protohemin IX by paper chromatography, visible spectroscopy, and mass spectrometry. Authentic protohemin IX dimethyl ester comigrated with the product of the oxonium salt reaction on paper chromatography with the $n$-propanol: kerosene solvent. As would be expected for a hemin dimethyl ester, the product of the oxonium salt reaction as well as the authentic protohemin IX dimethyl ester migrated at the solvent front on paper chromatography with lutidine-water-ammonia $(10: 7, \mathrm{v} / \mathrm{v}$, atmosphere saturated with $7 \mathrm{~N} \mathrm{NH}_{4} \mathrm{OH}$ ). Moreover, the reduced pyridine hemochrome derivatives of the products exhibited identical spectra. Confirmation of the structure was provided by mass spectrometry which showed a strong molecular ion at 644 and a prominent peak at 571, which corresponded to the expected loss of a $\mathrm{CH}_{2} \mathrm{CO}_{2} \mathrm{CH}_{3}$ group. 
Methylation of hematohemin. A sample of repurified hematohemin chloride was methylated, extracted, and dried using a scaled-down version of the procedure described for the protohemin IX. Chromatography of the product on polyamide with the acetic acid-benzene solvent revealed a major species with an $R_{f}$ of 0.56 . a minor species with an $R_{f}$ of 0.26 (presumably the monomethyl ester(s)), and a minor species with an $R_{f}$ of 0.81 (probably one of the difficult-to-remove impurities which contaminate other samples derived from commercial hematohemin (10)). There was no evidence for the presence in the reaction product of the free hematohemin starting material $\left(R_{f}\right.$ of 0.04$)$. Mass spectral analysis of the reaction product gave a pattern similar to that of protohemin IX dimethyl ester with a prominent peak at 644 , as expected.

In order to provide further evidence that $\mathrm{Me}_{3} \mathrm{OBF}_{4}$ had converted hematohemin to its dimethyl ester without conversion of the hydroxyl groups to methyl ethers the product was tested for its ability to be acetylated. Acetylation (14) was carried out in acetic anhydride $(37 \mu \mathrm{l})$-pyridine $(75 \mu \mathrm{l})$ at $37^{\circ} \mathrm{C}$ for $1 \mathrm{hr}$. The reaction was stopped by the addition of $250 \mu \mathrm{l}$ of water and the product was extracted with chloroform $(150 \mu \mathrm{l})$. Polyamide chromatography revealed one major product, with an $R_{f}$ of 0.76 , and very small amounts (a few percent) of slower migrating derivatives. The observed increase in $R_{f}$ upon acetylation is the change predicted for acetylation of a hydroxylated hemin to yield a hemin ester with less polarity and a more sterically hindered iron atom (10).

Methylation of heme $a$. A $0.74-\mathrm{mg}$ sample of heme a $(0.868 \mu \mathrm{mol})$ was dissolved in $0.036 \mathrm{ml}$ of diisopropylethylamine $(0.20 \mathrm{mmol}), 0.4 \mathrm{ml}$ of water. $9.0 \mathrm{ml}$ of $95 \%$ ethanol, and $0.6 \mathrm{ml}$ of $1.0 \mathrm{M}$ aqueous sodium bicarbonate. $\mathrm{Me}_{3} \mathrm{OBF}_{4}$ was added in 30-. 27-, and 22-mg batches at 5-min intervals (total of $0.53 \mathrm{mmol}$ ). During the reaction the flocculent sodium bicarbonate dissolved and carbon dioxide was evolved. Heme remained in solution throughout the methylation procedure. Aliquots of the reaction mixture were removed immediately before the second and third additions of $\mathrm{Me}_{3} \mathrm{OBF}_{4}$ and $10 \mathrm{~min}$ after the third addition. The samples were shaken with $2.5 \mathrm{vol}$ of chloroform and 5 vol of water. The chloroform phase, which contained all of the color, was washed and dried as described for protohemin dimethyl ester. Thin-layer chromatographic analysis on polyamide showed that after $5 \mathrm{~min}$ of methylation the heme a existed primarily as a derivative with an $R_{f}$ of 0.53 , presumably the dimethyl ester. The chromatogram showed smaller amounts of the free heme $a$ starting material $\left(R_{f}\right.$ of 0.02$)$ and a derivative with intermediate migration $\left(R_{f}\right.$ of 0.15$)$ which was assumed to be the monomethyl ester. After 10 min of reaction the two slower-migrating spots were faint and after the final treatment with methylating agent essentially all of the heme moved with an $R_{f}$ of 0.53 .

Paper chromatography and visible spectrophotometry provided further evidence that the final product was the dimethyl ester of heme $a$. The 
product moved with the solvent front in lutidine-water-ammonia and with an $R_{f}$ of 0.68 in propanol-kerosene. Hemins with one or more free carboxyl groups do not move at the solvent front in the lutidine-water-ammonia system and have no mobility in the propanol-kerosene system (15). The methylation derivative was isolated as the high-spin ferric form. The reduced pyridine hemochrome derived from the derivative was spectrally indistinguishable from the corresponding derivative of the starting material (absorption maxima at 430,533 , and $585 \mathrm{~nm}$ ), showing that no modification of the formyl or vinyl group occurred during methylation.

Evidence that the hydroxyl group of heme $a$ was not methylated by reaction with oxonium salt was provided by formation of an acetyl derivative of the heme $a$ methyl ester. Acetylation was carried out in pyridine $(100 \mu \mathrm{l})$-acetic anhydride $(50 \mu \mathrm{l})$ at $40^{\circ} \mathrm{C}$ for $15 \mathrm{~min}$ in a procedure similar to that used for the acetylation of free heme $a(1)$. The reaction was stopped with water and the heme derivatives isolated by chloroform extraction. Thin-layer chromatography on polyamide showed that approximately $80 \%$ of the heme $a$ had been converted to a less polar product $\left(R_{f}\right.$ of 0.78$)$ and the remainder ran as the unreacted dimethyl ester of heme $a\left(R_{f}\right.$ of 0.53$)$. Because of the degradation of heme $a$ which occurs under acetylation conditions (1), no attempt was made to bring the reaction to completion by carrying out the acetylation for longer times.

\section{DISCUSSION}

Trimethyloxonium tetrafluororborate has been commonly used as a methylating agent (11). Carboxyl groups of amino acids are esterified using an excess of the oxonium salt in neutral, aqueous solution without altering phenolic, alkyl hydroxyl, guanidino, or $\epsilon$-amino residues (12). The carboxylate anion is apparently far more reactive under these conditions than the other nucleophiles present. In this case, the reactivity of the solvent with the oxonium salt assures protection to hydroxyl and amino residucs but at the same time demands that an excess of reagent be used.

In the present study, benzilic acid was employed as a simple model compound to demonstrate that $\mathrm{Me}_{3} \mathrm{OBF}_{4}$ in aqueous solution esterifies carboxyl groups without methylating the $\alpha$-hydroxyl group. As expected, esterification proceeded rapidly and completely without reaction at the hydroxyl group.

$\mathrm{Me}_{3} \mathrm{OBF}_{4}$ proved to be an excellent methylating agent for hemes under neutral or basic conditions in a variety of solvent systems. In general, the reaction can be run in any hydroxylic solvent capable of solubilizing both the hemin as its carboxylic acid salt and as its methyl ester. We have found that in the presence of diisopropylethylamine, $86 \%$ aqueous ethanol functions satisfactorily in this regard for protohemin, the polar 
molecule hematohemin, and the nonpolar molecule heme $a$. With these hemins the reactions proceeded rapidly at room temperature, and at $0^{\circ} \mathrm{C}$, and reactions went essentially to completion if the oxonium salt was added in sufficient excess and in several aliquots. Excesses were modest in neutral solution and larger (up to 5000) in strongly basic conditions ( $\mathrm{pH} 13)$ where the oxonium salt is likely to be consumed rapidly by hydroxide ion. As a method for methylating unusually labile hemes, we recommend that the reaction be carried out at $0^{\circ} \mathrm{C}$ with a slight excess of $\mathrm{NaHCO}_{3}$ over oxonium salt to insure that the $\mathrm{pH}$ remains between 6 and 8 .

Care should be taken that the hemins remain soluble until methylation is complete. When protohemin is methylated in water, the reaction proceeds rapidly but a mixture of dimethyl ester, monomethyl ester, and free hemin precipitates from solution with the result that methylation is only $50 \%$ complete. The same phenomenon was observed upon methylation of heme $a$ in $20 \%$ aqueous methanol. Higher concentrations of methanol provide a more suitable solvent, but traces of monomethyl ester are observed when reaction proceeds in $90 \%$ aqueous methanol even after the addition of a larger excess of oxonium salt. Traces of an unesterified hemin were not observed with $86 \%$ aqueous ethanol as solvent.

The use of $\mathrm{Me}_{3} \mathrm{OBF}_{4}$ to esterify hemin carboxylate groups specifically without modifying other functional groups fulfills a critical need in heme chemistry. It is an excellent methylating agent regardless of polarity, lability, or multifunctionality of heme. The studies reported here demonstrate that the hydroxyl groups of hematohemin and the hydroxyl, formyl, and vinyl group of heme $a$ are not altered under these conditions. We also expect that ether, ester, ketal, and acetal linkages which may be present in complex hemes should survive unaffected and that porphyrins should be easily esterified under these conditions. This procedure then provides us with the possibility of establishing the structure of hemes which appear to be modified or cleaved by the acidic conditions of other methylating procedures.

\section{ACKNOWLEDGMENTS}

This study was supported by Research Grant AM-09250 and Training Grant GM-00187 from the U.S. Public Health Service. We are grateful to Ms. Gwedolyn Ball of the Department of Environmental and Industrial Health and Mrs. Peggy Johnson of the Department of Chemistry for mass spectrometry services. We would like to thank Dr. Richard Lawton for helpful discussions on this work. Dr. Takashi Yonetani for his kind gitt of purified hematohemin. and $\mathrm{Mr}$. William Odette for his help in the isolation of heme $a$.

\section{REFERENCES}

1. Caughey. W. S.. Smythe. G. A.. O’Keeffe, D. H.. Maskasky, J. E., and Smith. M. L. (1975) J. Biol. Chem. 250, 7602.

2. Clezy. P. S. and Morell, D. R. (1963) Biochim. Biophys. Acta 71, 150. 
3. DeFilippi, L. J., and Hultquist, D. E. (1975) Arch. Biochem. Biophys. 170, 670.

4. Hultquist, D. E.. Dean. R. T., and Reed. D. W. (1976) J. Biol. Chem. 251, 3927.

5. Smythe, G. A., and Caughey. W. S. (1970) Chem. Commun., 809.

6. Hultquist, D. E., and Dean. R. T. (1974) 168th Meeting. American Chemical Society Atlantic City, Biological Chemistry, 101.

7. Fisher, H., (1955) Org. Syn. Coll. 3, 442.

8. York. J. L., McCoy, S.. Taylor, D. N., and Caughey, W. S. (1967) J. Biol. Chem. 242, 908.

9. Paul, K. G.. Theorell, H., and Xkeson, А. (1953) Acta Chcm. Scand. 7, 1284.

10. Lamston, D. W., Coulson, A. F. W., and Yonetani. T. (1973) Anal. Chem. 45, 2273.

11. Curphey, T. J. (1971) Org. Syn. 51, 142.

12. Hamada. T., and Yonemitsu. O. (1971) Chem. Pharm. Bull. (Tokyo) 19, 1444.

13. Acree, S. F. (1904) Chem. Ber. 37, 2764.

14. Barrett, J. (1959) Nature (London) 183, 1185.

15. Chu, T. C.. and Chu. E. J.-H. (1955) J. Biol. Chem. 212, 1. 